\title{
Effect of soil structure on phosphate nutrition of crop plants
}

\author{
J. Prummel
}

Institute for Soil Fertility, Haren (Gr.), the Netherlands

Accepted: 25 November 1974

\section{Summary}

The effect of soil structure on phosphate nutrition of crop plants growing in a heavy, acid fluvial basin clay soil was studied in a trial with small filled-in concreteenclosed plots.

In confirmation with the literature in this field, crop growth was adversely affected by poor soil structure (small pore volume) and by a low phosphate content. A definite interaction of the two factors was observed; a higher phosphate availability being required on the soil with a poor structure.

The observed results and the interaction might be attributed to the influence of poor soil structure on root development and to the low phosphate mobility in the soil.

\section{Introduction}

It is generally recognized that severe soil compaction reduces plant growth and uptake of nutrients. On soils of poor structure root growth and activity may be restricted as a result of mechanical impedance and insufficient aeration. This restricted root development may hamper the utilization of applied fertilizers as a result of limited root contact with soil particles and the soil solution. The importance of root development is greatest for nutrients of low mobility, such as phosphorus.

Several research workers reported poor phosphate nutrition of crops on soils of a poor structure (cf. Wiersum, 1962). Lawton (1946), Flocker et al. (1959) and Flocker \& Nielson (1962) also found that soil compaction affected plant growth adversely and decreased phosphate uptake. Similar observations were obtained under field conditions in practice on soils that were severely compacted due to increased mechanization, resulting in plants with a stunted appearance.

Relatively little information is available regarding the need for phosphate as dependent on soil structure. The purpose of the present study was to investigate the interaction between soil structure and phosphate response of crop plants. In this investigation the phosphate need of the crop for maximum yields and its ability to get phosphorus from the soil were studied under various soil physical conditions. 
Table 1. Soil physical conditions. ${ }^{1}$

\begin{tabular}{|c|c|c|c|c|c|c|}
\hline \multirow{2}{*}{$\begin{array}{l}\text { Compaction } \\
\text { treatment }\end{array}$} & \multirow{2}{*}{$\begin{array}{l}\text { Bulk } \\
\text { density } \\
\left(\mathrm{g} / \mathrm{cm}^{3}\right)\end{array}$} & \multirow{2}{*}{$\begin{array}{l}\text { Pore } \\
\text { spacez }\end{array}$} & \multicolumn{2}{|c|}{ Air content ${ }^{2}$} & \multicolumn{2}{|c|}{ Available moisture ${ }^{2}$} \\
\hline & & & $\begin{array}{l}\text { at } \\
\text { sampling }\end{array}$ & at pF 2.0 & $\begin{array}{l}\text { at } \\
\text { sampling }\end{array}$ & at $\mathrm{pF} 2.0$ \\
\hline Very dense & 1.09 & 58.4 & 14.3 & 8.6 & 14.3 & 20.0 \\
\hline Dense & 1.04 & 60.4 & 17.4 & 11.3 & 14.6 & 20.7 \\
\hline Loose & 0.94 & 64.1 & 26.0 & 20.2 & 12.3 & 18.1 \\
\hline
\end{tabular}

1 We are indebted to Ir P. Boekel, who kindly made these determinations.

$2 \%$ of volume.

\section{Experimental method}

The investigation was carried out during five successive years on a heavy, acid fluvial basin clay soil ( $74 \%$ particles $<16 \mu \mathrm{m}, 6 \%$ organic matter, $\mathrm{pH}-\mathrm{n} . \mathrm{KCl} 4.7$ ) poor in phosphate in outdoor dug-in concrete containers of $1 \times 1 \mathrm{~m}$ with a depth of $80 \mathrm{~cm}$ and open bottom ends. The containers were filled with clay soil $(0-40 \mathrm{~cm})$ on a subsoil of yellow sand. To vary the structure, three degrees of compaction were carried out: a) by firmly tamping under wet conditions the successive 5 or 10 $\mathrm{cm}$ of the clay soil; b) by gently tamping under dry conditions; c) by loosely filling, with addition of Krilium Merloam (copolymer of vinyl acetate and maleic acid). This agent stabilizes a mechanically improved structure of clay soils without changing other fertility factors. During the experiment soil compaction was repeated three times in a period of five years. Soil physical determinations were made yearly in the 5 to $10 \mathrm{~cm}$ top layer during the growing season. The results, averaged over five years, are presented in Table 1.

Before filling the containers the soil was well mixed with different dressings of phoshate fertilizer (superphosphate) to obtain widely divergent phosphate contents (including a treatment without phosphate). The following crops were grown; spring barley in 1965, 1968 and 1969 (basal dressing $50 \mathrm{~kg} \mathrm{~N}$ per ha as calcium ammonium nitrate, $100 \mathrm{~kg} \mathrm{~K}, \mathrm{O}$ as potassium magnesium sulphate), flax in 1966 (basal dressing $25 \mathrm{~kg} \mathrm{~N}$ per ha as calcium nitrate, $150 \mathrm{~kg} \mathrm{K.2}$ as potassium magnesium sulphate), and sugar-beets in 1967 (basal dressing $150 \mathrm{~kg} \mathrm{~N}$ per ha as calcium ammonium nitrate, $200 \mathrm{~kg} \mathrm{~K}_{2} \mathrm{O}$ as potassium chloride).

Each spring a shallow seedbed was prepared, the basal dressings were harrowed in to a depth of 3 to $5 \mathrm{~cm}$ and subsequently the crop was sown. Soil tillage operations in autumn after harvesting the crop were restricted to shallow digging.

All treatments $(3$ structure levels $\times 4$ phosphate levels) were in duplicate ( 2 randomized blocks).

At harvest time dry matter yield was determined and the plant material was analysed for phosphate (barley grain and straw, flax grain and straw, sugar-beet roots and tops). 


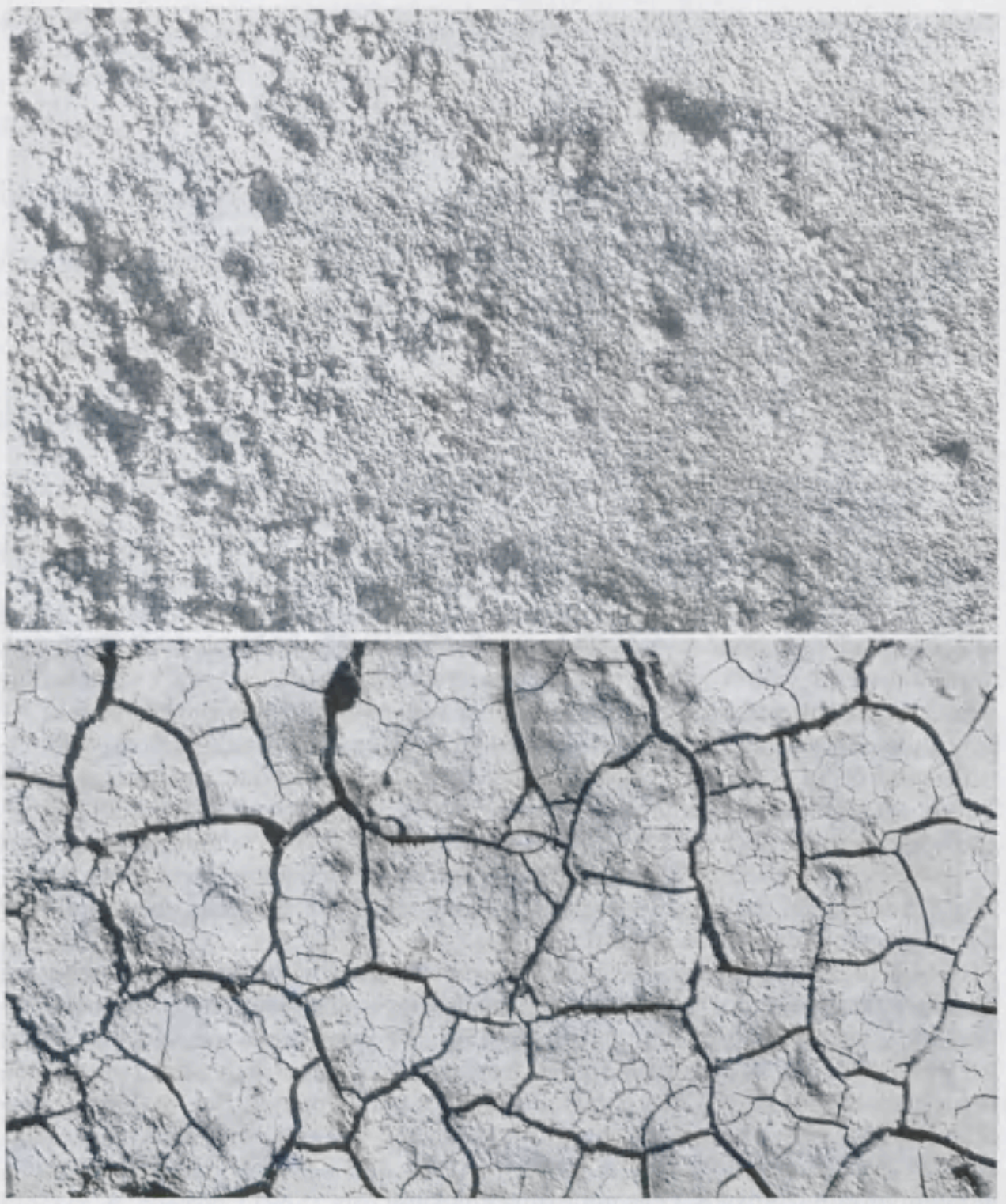

Fig. 1. Effect of compaction on the structure of the clay soil investigated. Top: non-compacted; bottom: severely compacted.

\section{Results}

\section{Yield}

In all years compaction had a harmful influence on soil structure, resulting in a very marked effect on porosity as indicated in Table 1 and illustrated in Fig. 1. 
The plots with a poor, dense structure were characterized by a hard surface crust, and those with a favourable structure by a surface mainly consisting of crumbs, partly combined into porous aggregates. Topsoil porosity was lowest under severe compaction (Table 1). During the growing seasons the weather conditions were rather wet and the moisture content was mostly sufficient. In soil with a poor structure the air content ranged in the different years from 6 to $14 \%$ of total volume at $\mathrm{pF} 2.0$. This is below the critical value of $15 \%$ of total volume, which is considered to be the minimum air percentage needed for good plant growth on heavy clay soils (Boekel, 1963).

Crop growth and yields responded very clearly to soil structure. In all years
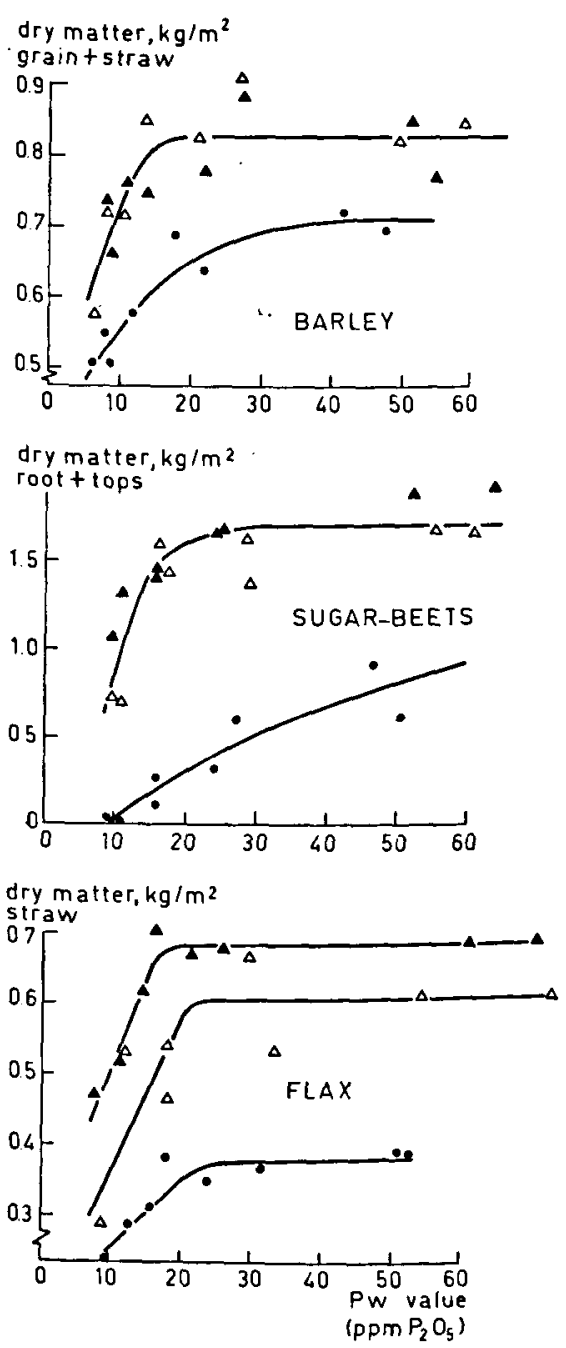

Fig. 2. Relation between soil $P_{2} O_{5}(\mathrm{mg} / 1, P w$ value) and yield of barley, sugar-beets and flax as affected by soil compaction.

Dots: severely compacted; open triangles: moderately compacted; solid triangles: non-compacted.

Neth. J. agric. Sci. 23 (1975) 
yields were higher on plots with a favourable soil structure, owing to factors other than phosphate (Fig. 2). Especially in 1967 for beets, which are known to be susceptible to an unfavourable soil structure, the effect was pronounced: at the optimum phosphate level the yield was nearly halved. It is beyond the scope of this study to discuss these differences in detail.

With increasing phosphate levels of the soil dry matter yields increased strongly. In Fig. 2 the yields for barley in 1969, beets and flax obtained at three levels of soil structure have been related to the water-extractable soil phosphate, designated as the $\mathrm{Pw}$ value in ppm $\mathrm{P}_{2} \mathrm{O}_{5}$ (van der Paauw, 1971). The relations can be presented by curves with a maximum, except for beets on soil of poor structure.

The curves show distinct differences in optimum $\mathrm{Pw}$ values between the different structure levels. On soil of good structure the maximum yield was attained at a Pw value of 18, 17 and 30 for barley, flax and beets, respectively. Under conditions of poor structure, however, a higher amount of available phosphate was needed for maximum yield: for barley, flax and beets 30,25 and at least $55 \mathrm{ppm}$, respectively. This indicates that phosphate availability is affected by the physical conditions of the soil. With a poor, dense structure the availability to the plants is less than with a favourable, crumble structure. On soils of poor structure the crops demand a higher content of water-extractable phosphate than on soils of good structure.

\section{Phosphate content}

With increasing phosphate levels of the soil plant phosphate, both in grain and straw, and in root and tops, also shows a distinct rise. An example is presented in Fig. 3 for barley (straw, three years' data). In this figure plant phosphate concentration is plotted against the $\mathrm{Pw}$ value of the soil, in the same way as for yields. Plant phosphate was hardly affected by soil physical conditions. Only for beets plant phosphate was lower on soils with a favourable structure. This may be partly attributed to the higher yields on soils of favourable structure, resulting in a decrease in phosphate concentration (dilution effect).

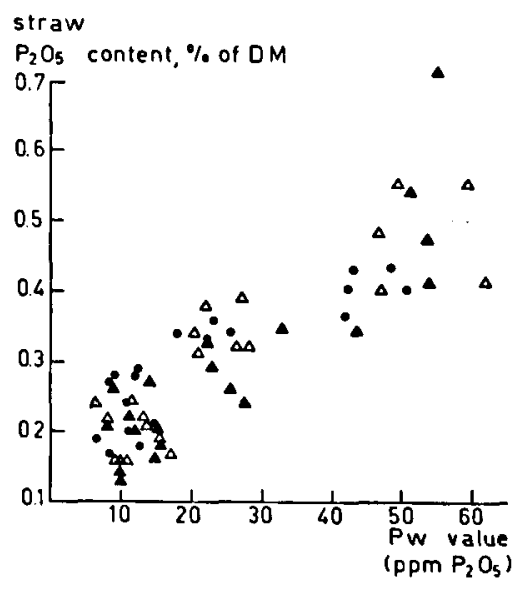

Fig. 3. Relation between soil $\mathrm{P}_{2} \mathrm{O}_{5}$ (mg/l, $\mathrm{Pw}$ value) and percentage phosphate in barley straw grown under different conditions of soil structure. Dots: severely compacted; open triangles: moderately compacted; solid triangles: non-compacted. 


\section{Discussion}

In this experiment phosphate deficiency on soils of poor structure was more severe than on those of good structure. Also on soils of poor structure crops demanded a higher content of water-extractable soil phosphate ( $\mathrm{Pw}$ value) for maximum yields. The interaction found between soil structure and phosphate response must be largely attributed to the influence of root development.

Wiersum (1962) demonstrated the influence of soil structure on root growth and uptake of nutrients in dependence of the mobility of the nutrient. He found a diminished uptake of phosphate with coarse aggregates when only few roots were developed. A more intensive rooting in finer substrates improved the utilization of phosphate. Nitrate uptake, however, was hardly influenced by rooting density on account of its high mobility. Similar results were obtained by Cornforth (1968), reporting that the uptake of phosphorus decreased as the rooting density decreased. The uptake of nitrogen was independent of rooting density. By contrast, Kuipers (1955) found in field experiments on clay soils that physical conditions even influenced the nitrogen requirements. In the case of an unfavourable soil structure optimum nitrogen dressings for sugar-beets were higher than on soils with a good structure.

Phosphate does not move readily in the soil and is concentration in the soil solution is low. In the transport of phosphate to the roots diffusion predominates over mass-flow. The movement by diffusion occurs only over very short distances. So a restricted root growth on poor structured soils limits the uptake of phosphate, as pointed out by Fried \& Broeshart (1967) and more recently again by Danielson (1972). Poor structure is accompanied by defects in phosphate supply, the crops demanding a higher content of soil phosphate and higher fertilizer dressings. An improved soil structure gives a better phosphate utilization by means of a more intensive root system and, therefore, a better contact with soil particles.

It is evident that differences in soil structure and, therefore, in root development can be partly responsible for the variable results of fertilizer experiments. Results of experiments have shown that notable differences in crop requirements can occur at equal nutrient contents of the soil. This might bear consequences for soil testing as a basis for fertilizer recommendations. At a given $\mathrm{Pw}$ value the need for fertilization may be higher on soils of poor structure relative to soils of good structure. Knowledge of soil structure in connection with root development is advisable to refine fertilizer recommendations on the basis of soil analyses.

\section{References}

Boekel, P., 1963. Soil structure and plant growth. Neth. J. agric. Sci. 11: 120-127.

Cornforth, I. S., 1968. Relationships between soil volume used by roots and nutrient accessibility. J. Soil Sci. 19: 291-301.

Danielson, R. E., 1972. Nutrient supply and uptake in relation to soil physical conditions. In: D. Hillel (Ed.), Optimizing the soil physical environment toward greater crop yields. Academic Press, New York, pp. 193-221.

Flocker, W. J., J. C. Lingle \& J. A. Vomocil, 1959. Influence of soil compaction on phosphorus absorption by tomato plants from an applied phosphate fertilizer. Soil Sci. 88: 247-250. 


\section{J. PRUMMEL}

Flocker, W. J. \& D. R. Nielsen, 1962. The absorption of nutrient elements by tomatoes associated with levels of bulk density. Proc. Soil Sci. Soc. Am. 26: 183-186.

Fried, M. \& H. Broeshart, 1967. The soil-plant system in relation to inorganic nutrition. Academic Press, New York.

Kuipers, H., 1955. A regional investigation into the relation between soil structure, yield of sugar beets and nitrogen supply. Neth. J. agric. Sci. 3: 170-181.

Lawton, K., 1946. The influence of soil aeration on the growth and absorption of nutrients by corn plants. Proc. Soil Sci. Soc. Am. 10: 263-268.

Paauw, F. van der, 1971. An effective water extraction method for the determination of plantavailable soil phosphorus. Pl. Soil 34: 467-481.

Wiersum, L. K., 1962. Uptake of nitrogen and phosphorus in relation to soil structure and nutrient mobility. Pl. Soil 16: 62-70. 